\title{
Current signature analysis to monitor DFIG wind turbine generators: A case study
}

\author{
Estefania Artigao $^{\mathrm{a}}$, Andres Honrubia-Escribano ${ }^{\mathrm{a}, \mathrm{b}}$, Emilio Gomez-Lazaro ${ }^{\mathrm{a}, \mathrm{b}}$ \\ ${ }^{a}$ Renewable Energy Research Institute \\ ${ }^{b}$ DIEEAC-EDII-AB University of Castilla - La Mancha
}

\begin{abstract}
As wind energy continues to develop with increasing wind turbine power capacities often deployed offshore, reducing operation and maintenance costs have become a critical aspect. Condition monitoring has been found to be the key to achieve this goal. Under this framework, the induction generator of a wind turbine is a major contributor to failure rates and downtime where doublyfed induction generators are the dominant technology employed. This paper presents a spectral analysis of a real doubly-fed induction generator of an inservice wind turbine. A one-year measurement campaign on an operating wind turbine has been used to perform the study. Three test cases representing different wind turbine operating conditions are presented to illustrate the results. All the peaks found in the spectra have been identified, and the frequency components related to electrical rotor unbalance have been found. The results show which components are more suitable for effective condition monitoring.
\end{abstract}

Keywords: Doubly-fed induction generator; current signature analysis; condition monitoring; wind turbine.

\section{Introduction}

Predictive maintenance based on condition monitoring is currently recognised as the most efficient maintenance strategy for wind turbines [1] where condition monitoring is the key to reduce operation and maintenance (O\&M) costs [2], leading to increased reliability and availability of wind turbines [3].

The induction generator contributes significantly to the overall failure rates and downtime of a wind turbine and therefore to operation and maintenance costs [4]. Doubly-fed induction generators (DFIGs) have been identified as the dominant energy conversion systems for variable speed wind turbines [5-8].

The different condition monitoring techniques available for induction generators of wind turbines are introduced in Section 2 where current signature analysis has been acknowledged as the best option [5,9]. The interpretation of

Email address: Estefania.Artigao@uclm.es (Estefania Artigao)

Preprint submitted to Elsevier

July 6, 2017 
the current spectra is of major importance since spectral components can arise from both normal operating conditions as well as faulty ones [10, 11].

Failure data analyses of real operating wind turbines are rarely presented. Based on the literature review presented below and to the best of our knowledge, there is a lack of current signature analyses applied specifically to in-service wind turbine DFIGs. Furthermore, unlike common studies where faults are known before the analysis is carried out and hence the authors know which faulty frequencies to target, a whole set of faulty frequencies is calculated in the present work in order to diagnose a real operating wind turbine. The present case study will also serve to identify which fault frequency components are most suitable to monitor the health of a DFIG.

In addition to this introduction, the paper is structured as follows: Section 2 provides the literature review on condition monitoring of induction machines with particular focus on doubly-fed induction generators and their applications to wind turbines. Section 3 describes the methodology used in the present work, which is based on current signature analysis. A detailed description of the formulae involved is presented. Section 4 describes the data available and used for the present analysis. In Section 5 the results obtained for three test cases are presented, while the results are discussed in Section 6. Finally, the conclusions extracted from the study and the main ideas for future work are summarised in Section 7.

\section{Literature Review}

The state of the art on condition monitoring of induction machines is presented in this section, first in general, and then focused on wind turbine DFIGs. It includes common faults, monitoring methods based on electrical measurements and signal processing techniques.

Condition monitoring is used to provide "continuous information on a component condition" [12] in order to detect incipient faults while components are still operational and appropriate actions can be planned to prevent major failure components [13]. In this scenario, appropriate data acquisition and advanced signal processing is crucial [14].

Recent surveys on the state of the art on condition monitoring and fault diagnostic technologies for the whole wind turbine are well described in $[15,16]$ and [1] for offshore wind turbines. The relationship between condition monitoring, diagnosis and maintenance is presented in [3] and, similarly in [12] with focus on wind farm maintenance strategies. A review focusing on faults that can be monitored using the wind turbine DFIG generator was published by [17].

From a more general point of view, induction machine's condition monitoring techniques include temperature, chemical and wear, mechanical vibration, electrical current, flux and power, electrical discharge and artificial intelligence $[9,18]$, where electrical signature analysis is the most common [19-21].

In addition to signal-based methods, there are other types of diagnosis techniques, which are model-based and knowledge-based. Recent model-based work 
has been published by [22] and [23], applied to stochastic non-linear systems under different types of disturbances. Regarding knowledge-based diagnosis, analysis based on SCADA is the current trend [24, 25].

The present paper discusses electrically-based condition monitoring techniques in induction generators with special focus on the doubly-fed architecture (DFIGs). The most common and critical faults found in induction generators are briefly introduced (see Section 2.1), the relevant current-based monitoring techniques discussed (see Section 2.2) and the available signal processing techniques identified (see Section 2.3).

\subsection{Faults in induction generators}

Failure statistics have reported that the induction generator is one of the major contributors to wind turbine failures [26-28]. Different classifications for induction generator faults have been found in the literature: mechanical and electrical, rotor and stator, per component, etc. In [10] it is stated that $40 \%$ of the generator faults are related to bearings, $38 \%$ to the stator, $10 \%$ to the rotor and the rest are categorised as "others". According to [27], 31\% of generator faults are slip rings issues, $12 \%$ bearing related, $8 \%$ grease and pipes, $7 \%$ rotor faults and $4 \%$ fan problems; the remaining $38 \%$ are not specified. Stator faults are identified as critical by [18] and [20].

Any fault that occurs in either the stator or rotor side of the machine, such as resistance variations or short circuits, will produce a phase asymmetry caused by a change in the phase impedances [29]. Normally, faults evolve from an incipient stage to a more severe condition, thus, early detection of any anomaly, such as resistance changes and winding unbalances, can avoid critical faults and reduce downtime periods [30]. A comprehensive survey of failure data, root causes and failure modes is presented in [9].

For variable-speed induction machines, studies claim that $45 \%$ of the failures are related to the stator and rotor parts [31]. According to [5], around $80 \%$ of mechanical faults eventually lead to eccentricity and DFIGs are more prone to eccentricity for a number of reasons. The failures and failure mechanisms in power electronic converters and generators in the context of their use in wind turbines is well analysed in [4].

\subsection{Electrically-based condition monitoring techniques}

It has already been mentioned that condition monitoring based on electrical measurements seems to be the trend towards efficient O\&M for induction generators; it is cheaper than other common techniques and can monitor both electrical and mechanical faults [5]. Such techniques include: current, voltage, instantaneous power and flux analysis [32,33]. Stator current analysis is the most common of these techniques $[5,6]$.

Current signature analysis based on stator current has been studied for doubly-fed induction generator based wind turbines but only validated using mathematical models and test rigs $[8,34,35]$ to detect rotor and stator asymmetries or bearing faults. Other signals, such as rotor currents, voltage or power 
signals have been used by $[6,36,37]$ on DFIG-based simulations and laboratory test rigs. In these studies, eccentricity is the target fault. Further modelling approaches have been proposed by $[7,38,39]$ capable of representing inter-turn short circuit, rotor and stator asymmetries or winding faults.

It can be highlighted that further research is required by the wind power industry not only to validate the models previously commented but also to complement the laboratory tests with real operating wind turbines. A lack of field measurement campaigns for current signature analysis has been detected. Under this framework, the present paper provides a thorough analysis on an in-service $850 \mathrm{~kW}$ DFIG wind turbine.

\subsection{Signal Processing}

Once the monitoring technique is chosen, the signal processing methodology plays a key role. Various signal processing techniques can be applied to electrical measurements towards fault identification. These are classified into time-domain, frequency domain and time-frequency [40].

Time-domain analysis consists of analysing the time waveform itself by extracting characteristic features from descriptive statistics such as mean, root mean square (rms), peak, peak- to-peak interval, standard deviation, shape factor, crest factor, skewness, kurtosis, etc. [12].

Frequency-domain analysis transforms the waveform signal from the time domain to the frequency domain. The advantage of this last method over timedomain analysis is its ability to identify frequency components of interest [41]. The most common method is spectrum analysis via the Fast Fourier Transform (FFT), which is widely used for fault diagnosis because the variations of certain harmonic components in the frequency spectrum of a signal can be related to a specific fault type [14].

Frequency-domain analysis is limited to stationary waveform signals but, due to both the variable-speed nature of wind turbine operation and the unsteady load condition involved, time-frequency analyses have been developed and are widely accepted as key signal processing tools [42]. Short-Time Fourier Transform (STFT) and Wigner-Ville distribution are the most popular timefrequency distributions [41].

Other less common time-frequency techniques applied to wind generator fault detection are Hilbert transform [43], Gabor transform [44], Chirplet transform $[45,46]$ or amplitude-demodulation [35].

\section{Methods}

Current signature analysis is based on the principle that each fault has its own effect on the current spectra. Fault frequency components related to the faults described in Section 2.1 have been known for long time. Their formulae have been identified and demonstrated for different kinds of induction machine configurations (motor, generator) and architectures (squirrel cage, wound rotor), and for different industries, including a few specific cases in wind turbines quite 
recently, as described in Section 2.2. From the signal processing techniques presented in Section 2.3, FFT has been chosen for the case study presented in this paper (Section 4).

The above-mentioned formulae are presented below. They have been applied to the wind turbine under study in order to identify the different peaks found in the spectra for the test cases presented in Section 5.

Certain parameters (in terms of architecture and nominal values) of the induction machine must be identified in order to be able to apply the formulae presented in this section. These are the supply frequency (referred to as $f_{s}$ ), the number of pole pairs $(p)$, the number of rotor slots $(R)$ and the slip $(s)$. In this line, there are some frequency components inherent to the induction machine that usually modulate its current, together with other factors; these are the slip frequency $\left(f_{2}\right)$, the mechanical rotor speed in hertz $\left(f_{r}\right)$, and the rotor slot passing frequency $\left(S_{e}\right)$, defined as:

$$
\begin{gathered}
f_{2}=s f_{s} \\
f_{r}=f_{s} \frac{1-s}{p} \\
S_{e}=R f_{r}
\end{gathered}
$$

\subsection{Broken Rotor Bars, fbrb}

Broken rotor bars can be caused by heavy duty cycles, pulsating mechanical loads or imperfections during fabrication or machine's assembly [47]. These result in electric and magnetic asymmetry in the rotor of induction machines, producing frequency components in the stator current given by [48]:

$$
f_{b r b}=f_{s} \pm 2 s f_{s}
$$

Since a minimal degree of asymmetry will always be introduced during manufacturing, the mere presence of these frequency components might not imply a fault. Many authors have reported the amplitude level needed for the frequency components obtained with Eq. (4) to be able to diagnose broken rotor bars $[18,49]$, it must show less than $25 \mathrm{~dB}$ difference with the supply frequency amplitude. A severity factor is presented in [48] and [50].

As frequency components given by Eq. (4) overlap with other type of faults and fall too close to the supply frequency, other spectral components have been proposed in the literature, aimed at facilitating their identification. These are given by $[10,50]$ :

$$
f_{b r b}=f_{s}\left[\kappa\left(\frac{1-s}{p}\right) \pm s\right]
$$

Where $k$ is the harmonic index $(\kappa=1,2,3, \ldots)$. The authors in $[11,21]$ established the relation $\kappa / p=1,5,7, \ldots$ because of the normal winding configurations. 


\subsection{Bearing Damage, $f_{b e}$}

Bearings are a major contributor to generator component failures $[4,10]$, the main reason being its incorrect installation or that of the shafts they hold [50]. The fact that the rotor shaft is supported by bearings will cause a radial movement between rotor and stator when the bearings are defective. This mechanical displacement produces stator currents at frequencies given by [19]:

$$
f_{b e}=\left|f_{s} \pm m f_{o, i}\right|
$$

Where $f_{o, i}$ refers to bearing outer and inner race faults respectively. In order to calculate those frequency components, detailed information about the bearing type and dimension is required. As an alternative, the following simplifications have been proposed in the literature [21, 47]:

$$
\begin{aligned}
f_{o} & =0.4 N_{b} \frac{f_{s}(1-s)}{p} \\
f_{i} & =0.6 N_{b} \frac{f_{s}(1-s)}{p}
\end{aligned}
$$

Such simplifications are valid for most bearings between eight and twelve balls, which falls within the established range for the wind turbine analysed in the present work.

\subsection{Stator Winding, $f_{\text {st }}$}

Stator winding faults start as inter-turn short circuits $[50,51]$ as a result of the insulation's wear between the individual coils, which is in practice a stator phase winding's short circuit [52]. A negative magnetomotive force is thus initiated when the short-circuit current flows in the inter-turn short-circuit windings. This reduces the net magnetomotive force, changing the air-gap flux, which induces harmonic frequencies in the stator current given by Eq. (9), [50, 51]:

$$
f_{s t}=f_{s}\left[\kappa\left(\frac{1-s}{p}\right) \pm n\right]
$$

Where $k=1,2,3, \ldots$, and $n=1,3,5, \ldots$.

\subsection{Air Gap Eccentricity, $f_{\text {ecc }}$}

Eccentricity faults are classified into three groups: static, dynamic and mixed eccentricity [53]. In static eccentricity the rotating axis moves away from the stator axis but it matches with the rotor axis. It is mainly caused by miss circularity of the stator core, improper installation of the shaft (rotor position) or inaccurate manufacturing. Dynamic eccentricity takes place when the rotating axis does not coincide with rotor but it does with stator's axis, typically caused by wrong positioning of shaft or bearings and bearing wear. Mixed eccentricity is the co-existence of both types of eccentricities. 
Spectrum components affected by eccentricity fault have been divided in two main groups in: high and low frequency components (HF and LF respectively). $\mathrm{HF}$ components arise around the principal slot harmonic (PSH) and can be calculated as $[11,53]$.

$$
f_{e c c, H F}=f_{s}\left[ \pm \nu+\left(\kappa R \pm n_{d}\right) \frac{1-s}{p}\right]
$$

where $\kappa$ is an integer $(\kappa=1,2,3, \ldots), n_{d}$ is the eccentricity order $\left(n_{d}=0\right.$ for static eccentricity and $n_{d}=1,2,3, \ldots$ for dynamic eccentricity), and $\nu$ is the order of stator time harmonics $(\nu=1,3,5,7, \ldots)$. HF components are less influenced by load torque oscillations and load variations [53]. Another advantage is their ability to separate the spectral components of air-gap eccentricity from those of broken rotor bars. However, detailed information of the machine's assembly is required [11].

LF components arise around the supply frequency and are intensified when mixed eccentricity occurs. The main disadvantage is their coincidence with oscillating torque effects [53]. They are calculated as [11]:

$$
f_{e c c, L F}=f_{s} \pm \kappa f_{s} \frac{1-s}{p}
$$

\subsection{Rotor Unbalance, $f_{R U}$}

The analytical expressions for the origins of stator harmonic content caused by rotor winding or brush gear unbalance asymmetries are discussed in $[7,8]$. They differentiate between healthy and faulty related frequency components, which are given by Eqs. (12) and (13) respectively:

$$
\begin{aligned}
& f_{H R U}=f_{s}|6 \kappa(1-s) \pm l| \\
& f_{F R U}=f_{s}\left|\frac{\kappa}{p}(1-s) \pm l\right|
\end{aligned}
$$

Where $\kappa$ is an air-gap field space harmonic constant $(\kappa=1,2,3, \ldots)$, and $l$ is the supply time harmonic one $(l= \pm 1)$. In $[6-8]$, the authors clarify that it might not be possible to identify all these frequency components since they can be influenced by machine configurations or in-service conditions.

\subsection{Summary}

The most common faults and their main root causes have been introduced, these being specific component's wear and imperfections during manufacturing and assembly.

It can therefore be deduced that certain defects will give rise to other component faults. I.e. the change in the air-gap flux produced by a fault in the stator winding (given by equation (9)) will result in air gap eccentricity (given by equation (11)).

Deriving from equation (9) with $n=1$ : 


$$
f_{s}\left[\kappa\left(\frac{1-s}{p}\right) \pm 1\right]=\kappa f_{s} \frac{1-s}{p} \pm f_{s}
$$

Which corresponds to the formulae given by equation (11).

Similarly, any asymmetry present in the stator winding impedances will cause a resultant backward rotating field that will affect the rotor currents [47]. I.e. any fault coming from the stator will affect the rotor, and viceversa. Deriving from (14) the same components are obtained than those given by equation (13) with $l=1$ :

$$
f_{s}\left|\frac{\kappa}{p}(1-s) \pm l\right|=f_{s}\left|\frac{\kappa}{p}(1-s) \pm 1\right|=\kappa f_{s} \frac{1-s}{p} \pm f_{s}
$$

The same occurs regarding frequency components introduced by rotor bars. It has been mentioned that a minimal degree of asymmetry will always be introduced during manufacturing or assembly, generating frequency components given by equations (4) and (5) which might not be faulty indicators by themselves. In fact two components from equation (5) overlap with two from (12) referring to a healthy state of the induction machine.

For the left component of (5) with $\kappa / p=5$ :

$$
f_{s}[5(1-s)-s]=5 f_{s}-6 s f_{s}
$$

and the right one with $\kappa / p=7$ :

$$
f_{s}[7(1-s)+s]=7 f_{s}-6 s f_{s}
$$

Considering the left and right components given by equation (12) with $\kappa=1$ :

$$
\begin{aligned}
& f_{s}|6(1-s)-1|=5 f_{s}-6 s f_{s} \\
& f_{s}|6(1-s)+1|=7 f_{s}-6 s f_{s}
\end{aligned}
$$

\section{Case study}

The data used for the present analysis have been extracted from a database developed and maintained by the Spanish company Ingeteam. It consists of data collected during one year of wind turbine operation, from September 2015 to September 2016. Ingeteam specialises in power converters, generators, turbine controllers, Condition Monitoring Systems and SCADA Systems. They also provide O\&M services and installation services. They have equipped $30 \mathrm{GW}$ of wind power worldwide, $5 \mathrm{GW}$ of which correspond to O\&M activities (covering more than 3,500 wind turbines).

The gathered data comprises vibration, humidity, temperature, currents and voltages from various sensors located in different parts of the wind turbine. Several acquisitions were programmed with different sampling parameters (sam-

pling rate, in Hertz, and sampling time, in seconds), with the aim of covering 
a wide range of frequencies without compromising the data transfer by acquiring lengthy signals. Table 1 summarises the types of files available for each acquisition.

\begin{tabular}{|c|c|c|c|c|c|c|c|c|}
\hline \multirow[b]{2}{*}{ Label } & \multirow[b]{2}{*}{ Signal } & \multirow[b]{2}{*}{ Sensor Location } & \multicolumn{6}{|c|}{ Sampling Parameters } \\
\hline & & & $\begin{array}{c}1.5 \mathrm{kHz} \\
11.9 \mathrm{~s}\end{array}$ & $\begin{array}{c}750 \mathrm{~Hz} \\
21.8 \mathrm{~s}\end{array}$ & $\begin{array}{c}1.5 \mathrm{kHz} \\
5.4 \mathrm{~s}\end{array}$ & $\begin{array}{c}24 \mathrm{kHz} \\
0.3 \mathrm{~s}\end{array}$ & $\begin{array}{c}48 \mathrm{kHz} \\
0.1 \mathrm{~s}\end{array}$ & $\begin{array}{c}1 \mathrm{kHz} \\
0.1 \mathrm{~s}\end{array}$ \\
\hline ELOAR & vibration & gearbox planetary stage radial & $\mathrm{x}$ & $\mathrm{x}$ & $\mathrm{x}$ & $\mathrm{x}$ & $\mathrm{x}$ & \\
\hline EPAX & vibration & main shaft axial & $\mathrm{x}$ & $\mathrm{x}$ & $\mathrm{x}$ & $\mathrm{x}$ & $\mathrm{x}$ & \\
\hline EPR & vibration & main shaft radial & $\mathrm{x}$ & $\mathrm{x}$ & $\mathrm{x}$ & $\mathrm{x}$ & $\mathrm{x}$ & \\
\hline ERAR & vibration & gearbox high speed shaft drive end radial & $\mathrm{x}$ & $\mathrm{x}$ & $\mathrm{x}$ & $\mathrm{x}$ & $\mathrm{x}$ & \\
\hline ERAX & vibration & gearbox high speed shaft non drive end axial & $\mathrm{x}$ & $\mathrm{x}$ & $\mathrm{x}$ & $\mathrm{x}$ & $\mathrm{x}$ & \\
\hline GAR & vibration & generator drive end radial & $\mathrm{x}$ & $\mathrm{x}$ & $\mathrm{x}$ & $\mathrm{x}$ & $\mathrm{x}$ & \\
\hline GAX & vibration & generator drive end axial & $\mathrm{x}$ & $\mathrm{x}$ & $\mathrm{x}$ & $\mathrm{x}$ & $\mathrm{x}$ & \\
\hline GOAR & vibration & generator non drive end radial & $\mathrm{x}$ & $\mathrm{x}$ & $\mathrm{x}$ & $\mathrm{x}$ & $\mathrm{x}$ & \\
\hline IestR & current & stator current phase a & & & $\mathrm{x}$ & $\mathrm{x}$ & $\mathrm{x}$ & \\
\hline IestS & current & stator current phase b & & & $\mathrm{x}$ & $\mathrm{x}$ & $\mathrm{x}$ & \\
\hline IestT & current & stator current phase $\mathrm{c}$ & & & $\mathrm{x}$ & $\mathrm{x}$ & $\mathrm{x}$ & \\
\hline IinvR & current & rotor-side converter current phase a & & & $\mathrm{x}$ & $\mathrm{x}$ & $\mathrm{x}$ & \\
\hline Iinvs & current & rotor-side converter current phase $b$ & & & $\mathrm{x}$ & $\mathrm{x}$ & $\mathrm{x}$ & \\
\hline IinvT & current & rotor-side converter current phase $\mathrm{c}$ & & & $\mathrm{x}$ & $\mathrm{x}$ & $\mathrm{x}$ & \\
\hline IrecR & current & grid-side converter current phase a & & & $\mathrm{x}$ & $\mathrm{x}$ & $\mathrm{x}$ & \\
\hline IrecS & current & grid-side converter current phase $b$ & & & $\mathrm{x}$ & $\mathrm{x}$ & $\mathrm{x}$ & \\
\hline IrecT & current & grid-side converter current phase c & & & $\mathrm{x}$ & $\mathrm{x}$ & $\mathrm{x}$ & \\
\hline VBus & voltage & voltage $\mathrm{DC}$ bus & & & $\mathrm{x}$ & $\mathrm{x}$ & $\mathrm{x}$ & \\
\hline VGenS & voltage & voltage stator phase b & & & $\mathrm{x}$ & $\mathrm{x}$ & $\mathrm{x}$ & \\
\hline VGenT & voltage & voltage stator phase c & & & $\mathrm{x}$ & $\mathrm{x}$ & $\mathrm{x}$ & \\
\hline TBars & temperature & cabinet converter bars & & & & & & $\mathrm{x}$ \\
\hline TCCU & temperature & cabinet CCU converter & & & & & & $\mathrm{x}$ \\
\hline TIGBTs & temperature & cabinet IGBTs converter & & & & & & $\mathrm{x}$ \\
\hline HumConv & humidity & cabinet converter & & & & & & $\mathrm{x}$ \\
\hline HumIGBTs & humidity & cabinet IGBTs converter & & & & & & $\mathrm{x}$ \\
\hline
\end{tabular}

Table 1: Summary of the signals acquired from the wind turbine under study.

The triggers set to start an acquisition are described as follows:

(1) Rise in load over $75 \%$, i.e. when the rms current exceeds $630 \mathrm{~A}$ in the three phases of the stator.

(2) Rise in load over $60 \%$, i.e. when the rms current exceeds $500 \mathrm{~A}$ in the three phases of the stator.

(3) Connected, i.e. when the rms current for one of the phases reaches $300 \mathrm{~A}$ (this is $45 \%$ of the generator load, approximately).

(4) Periodically, i.e. every 15 hours of no-acquisition (where none of the conditions previously described are met).

When any of the conditions from 1 to 3 are met for more than one hour, a new acquisition is triggered.

The aim of the present study is to analyse the doubly fed induction generator through stator current signature analysis via Fast Fourier Transform, i.e. spectrum peak search according to the formulae presented in Section 3. Rotorside and grid-side converter currents, as well as voltages, have been considered for the study, and their parameters extracted for calculations. Figure 1 shows the diagram for the doubly fed induction generator, indicating the location of current sensors. 


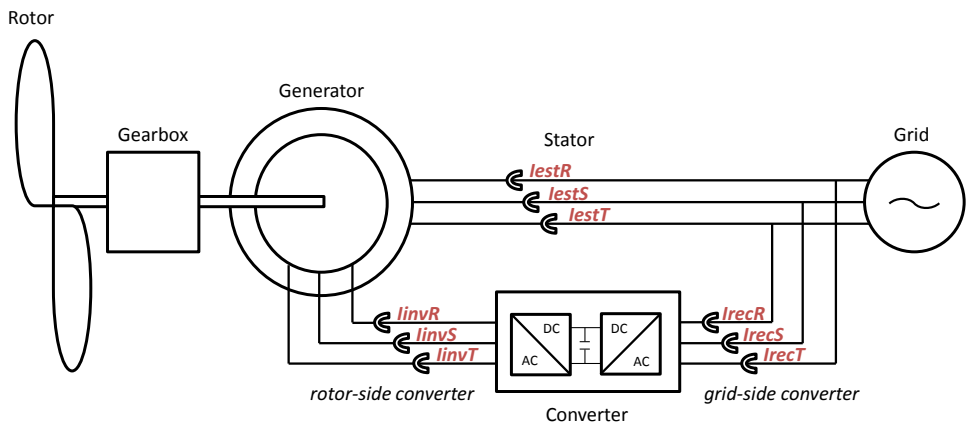

Figure 1: DFIG diagram with current sensors.

\section{Results}

The reported wind turbine is an $850 \mathrm{~kW}$ nominal power, 2 pole pair DFIG, Vstator 690 Vac, Vrotor 690 Vac. Three test cases have been selected to illustrate the analysis carried out, corresponding to the following wind turbine operating conditions:

- Test case 1. High load and super-synchronous speed.

- Test case 2. Low load and sub-synchronous speed.

- Test case 3. Lower load and lower sub-synchronous speed.

These test cases cover not only different states of load and rotational speed but also a wide slip range, from $-9 \%$ to $18 \%$.

The plots presented have been processed from the current signals with $1.5 \mathrm{kHz}$ and $5.4 \mathrm{~s}$ sampling parameters (see Table 1). The three test cases meet steadystate conditions in order to be able to undertake FFT analysis accurately. For the purpose of the study, a difference lower than $10 \%$ in the current's amplitude is considered as constant amplitude, i.e. steady-state condition.

All possible faulty frequencies presented in Section 3 have been calculated for each test case in order to identify which peaks might correspond to which fault (or faults) in the spectrum. It has been possible to identify all peaks of the three test cases as presented below.

\subsection{Test case 1. High load E⿱ super-synchronous speed}

The raw data for stator and rotor currents are shown in Figure 2, with a two-second zoom for a better appreciation of the waveform.

The signal reference number indicates the date and time the signal was registered, i.e. 20/01/2016 at 09:03:05. It can be appreciated from the waveforms that steady-state conditions are met. Calculations show less than $5 \%$ difference in the total current amplitude during the whole acquisition. Table 2 presents the main parameters extracted from the current waveforms. 

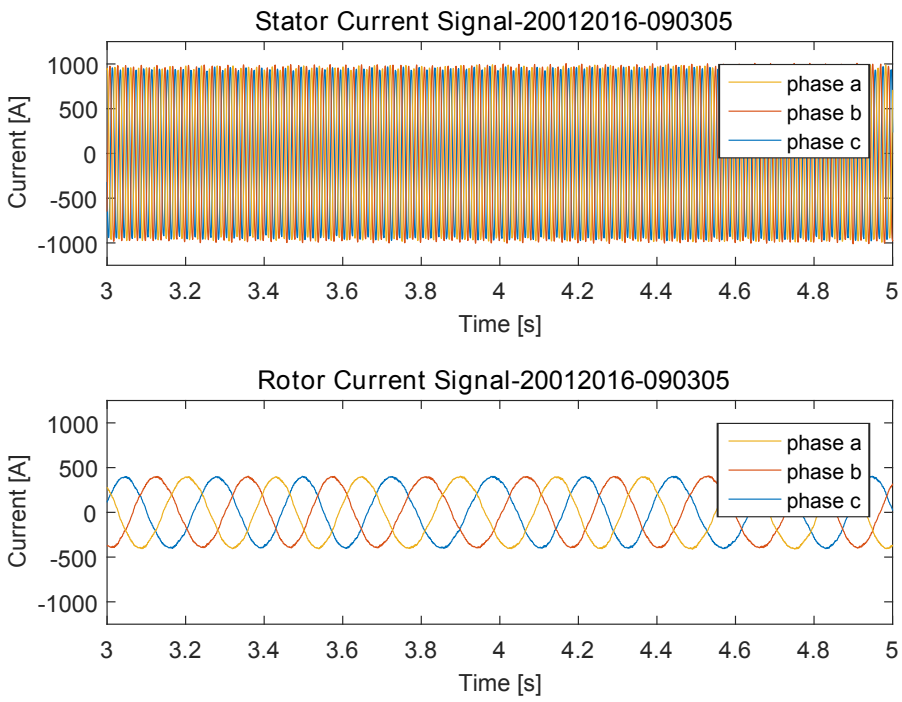

Figure 2: Stator and rotor currents for high load and super-synchronous speed (2 s zoom).

\begin{tabular}{l|c|c|c|c|c} 
& rms stator [A] & rms rotor [A] & f stator [Hz] & f rotor [Hz] & slip \\
\hline Phase a & 700.57 & 284.07 & & & \\
Phase b & 705.93 & 280.02 & 49.98 & 4.58 & -0.0915 \\
Phase c & 692.47 & 283.53 & & &
\end{tabular}

Table 2: Stator and rotor current parameters for signal 20012016-090305.

A difference of less than $2 \%$ in the rms amplitudes can be observed from one phase to the next in the stator and $1.5 \%$ in the rotor. Note that the highest rms amplitude is registered in phase b for the stator whereas for the rotor, the highest one corresponds to phase a. Despite these differences, the main frequencies are identical for the three phases both in stator and rotor.

The generator slip can be calculated dividing the supply frequency (main frequency of the stator) by the main frequency of the rotor, obtaining 0.0915 for this particular case. The negative sign is the convention for super-synchronous speed.

Then, FFT is applied to the stator current, and peak search and identification are carried out, as shown in Figure 3.

The supply frequency $(50 \mathrm{~Hz})$ and its harmonics (both odd and even) are clearly seen in the spectrum. The odd harmonics present higher amplitudes than the even ones, which indicates a certain level of supply unbalance [6]. When a phase-to-phase comparison is conducted, a difference is found for harmonic $150 \mathrm{~Hz}$, where the amplitude in phases a and $\mathrm{c}$ is around $10 \mathrm{~dB}$ smaller than in phase $b$, suggesting that the presence of an asymmetry impacts differently on each phase.

Another peak naturally present in the spectrum is that corresponding to the sum of the main frequency of the stator and the main frequency of the rotor: 


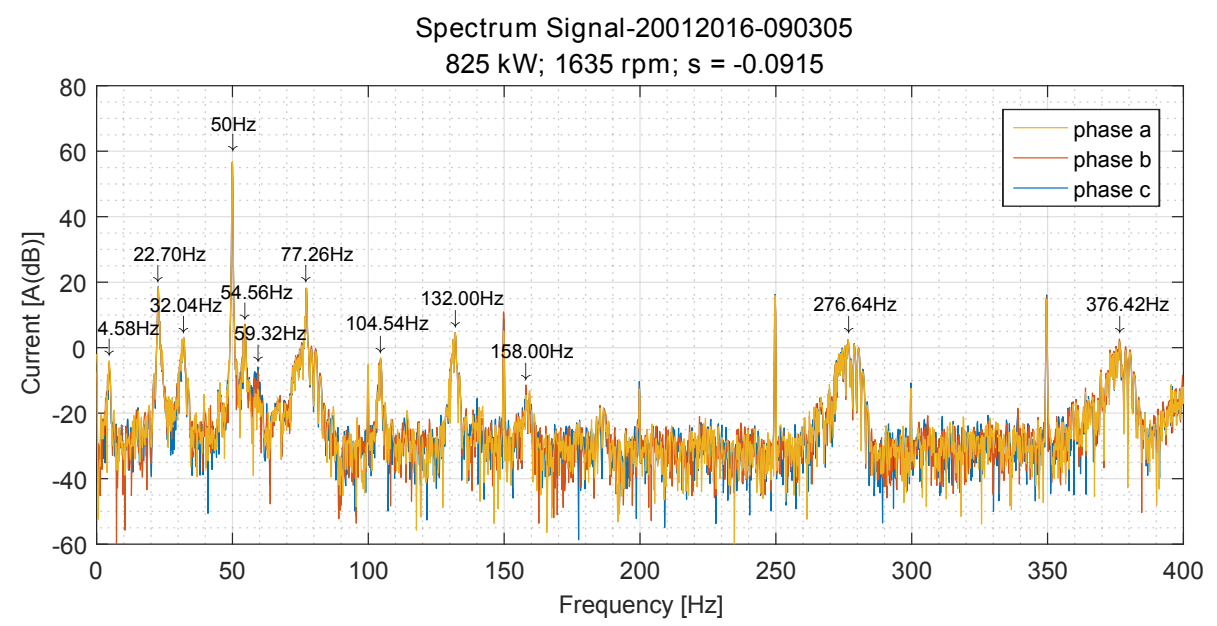

Figure 3: Frequency spectrum of stator current for signal 20012016-090305.

$54.56 \mathrm{~Hz}$ (oscillating torque effect [5]). For this test case, an amplitude of around $7 \mathrm{~dB}$ is obtained.

In order to find out to which faults the rest of the peaks belong to, all potential fault frequencies have been calculated and summarised in Table 3, as per the formulae described in Section 3.

\begin{tabular}{|c|c|c|c|c|}
\hline Fault & \multicolumn{4}{|c|}{ Frequencies $(\mathrm{Hz})$} \\
\hline \multirow{2}{*}{$f_{b r b}($ eq $(4))$} & 40.83 & & & \\
\hline & 59.13 & & & \\
\hline \multirow{2}{*}{$f_{b r b}($ eq $(5))$} & 49.98 & 269.19 & 377.30 & \\
\hline & 59.13 & 277.34 & 386.45 & \\
\hline \multirow{2}{*}{$f_{b e, o}($ eq $(7))$} & 37.31 & 124.59 & 211.88 & \\
\hline & 137.27 & 224.55 & 311.84 & \\
\hline \multirow{2}{*}{$f_{b e, i}($ eq $(8))$} & 80.95 & 211.88 & 342.80 & \\
\hline & 180.91 & 311.84 & 442.76 & \\
\hline \multirow{2}{*}{$f_{s t}(\mathrm{eq}(9))$} & 22.70 & 4.57 & 31.85 & \\
\hline & 77.26 & 104.53 & 131.81 & \\
\hline \multirow{2}{*}{$f_{e c c, H F}($ eq $(10))$} & 1932.06 & 2032.02 & 2131.98 & \\
\hline & 1986.62 & 2086.58 & 2186.54 & \\
\hline \multirow{2}{*}{$f_{e c c, L F}($ eq $(11))$} & 22.70 & 4.57 & 31.85 & \\
\hline & 77.26 & 104.53 & 131.81 & \\
\hline \multirow{2}{*}{$f_{H R U}($ eq $(12))$} & 277.34 & 604.66 & 931.98 & 1259.30 \\
\hline & 377.30 & 704.62 & 1031.94 & 1359.26 \\
\hline \multirow{2}{*}{$f_{F R U}($ eq $(13))$} & 22.07 & 4.57 & 31.85 & 59.13 \\
\hline & 77.26 & 104.53 & 131.81 & 159.09 \\
\hline
\end{tabular}

Table 3: Calculated fault frequencies for Signal 20012016-090305.

As explained in Section 3.6, fault frequency components corresponding to stator winding faults $\left(f_{s t}\right)$, low frequency air gap eccentricity $\left(f_{e c c, L F}\right)$ and faulty rotor unbalance $\left(f_{F R U}\right)$ overlap. It can be observed that these mentioned peaks 
do appear in the spectrum, as well as those corresponding to $f_{H R U}$ components.

Analysing the amplitudes of the peaks related to faulty components, it is possible to observe higher amplitudes for the odd sub-harmonics than for the even ones, sub-harmonic $\kappa=1$ (both left and right side-bands $l=-1$ and $l=1$ ) being the highest of them all. It can also be appreciated that all frequencies are present in the three phases with the same amplitude per phase except for sub-harmonic $\kappa=4$ and $l=-1$, where the amplitude is higher in phases $\mathrm{b}$ and $c$ than in phase a.

For the healthy related components $\left(f_{H R U}\right)$, only the first pair of harmonics $(\kappa=1$ with $l=-1$ and $l=1)$ can be seen, since the rest fall at frequencies higher than half of the signal's sampling frequency (hence not detectable), with an amplitude around $0 \mathrm{~dB}$. For this first pair of harmonics, several peaks close to one another suggesting a crest form are obtained due to the presence of peaks corresponding to $f_{F R U}$ of higher order sub-harmonics $(\kappa=12,14$ and $\kappa=16,18)$ around $f_{H R U}$. Similar results were reported in [6].

\subsection{Test case 2. Low load $\mathscr{E}$ sub-synchronous speed}

Test case 2 files were registered on 24/11/2015 at 12:57:54. Its stator and rotor currents are shown in Figure 4 again with a two-second zoom. Steady-state conditions are met with less than $5 \%$ difference in the total current amplitude for the whole waveform. Table 4 shows their main parameters.
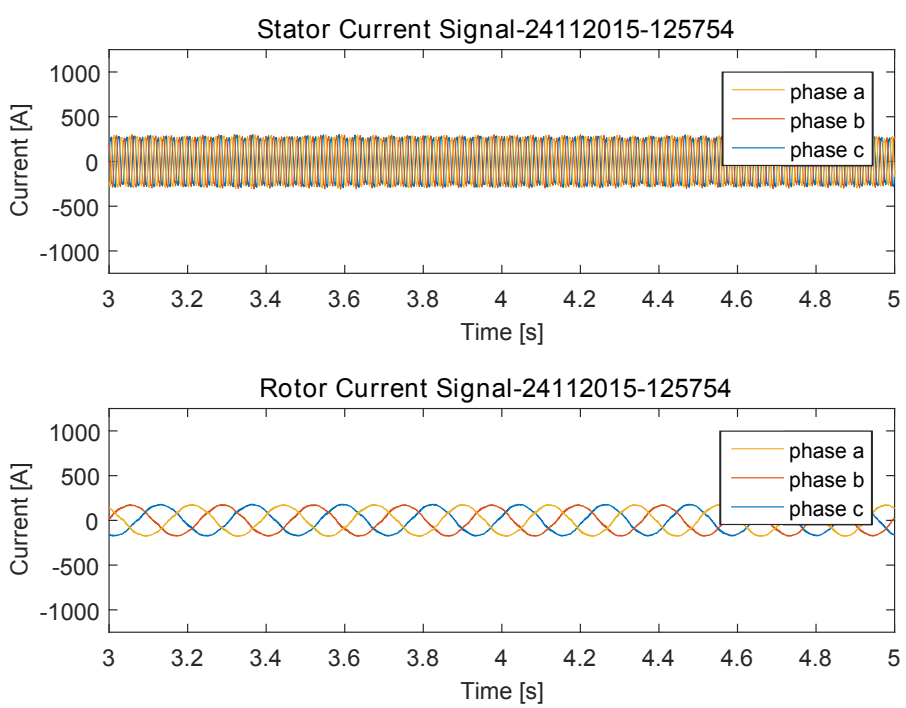

Figure 4: Stator and rotor currents at low load and sub-synchronous speed (2s zoom).

For this state, the difference in the rms amplitude is less than $1.7 \%$ for the stator and $1 \%$ for the rotor, where the highest values are found in phase a for both stator and rotor, although the amplitude values in a and c phases are nearly the same for the rotor. The main frequencies obtained are again identical 


\begin{tabular}{c|c|c|c|c|c} 
& rms stator $[\mathbf{A}]$ & rms rotor [A] & f stator $[\mathrm{Hz}]$ & f rotor $[\mathrm{Hz}]$ & slip \\
\hline Phase a & 198.41 & 122.69 & & & \\
Phase b & 195.01 & 121.70 & 49.99 & 4.21 & 0.0842 \\
Phase c & 197.43 & 122.64 & & &
\end{tabular}

Table 4: Stator and rotor current parameters for signal 24112015-125754.

for the three phases, in both stator and rotor, giving a slip of 0.0842 (note the positive sign indicating sub-synchronous speed).

Stator current spectrum is then calculated (Figure 5), and peak search and identification is carried out.

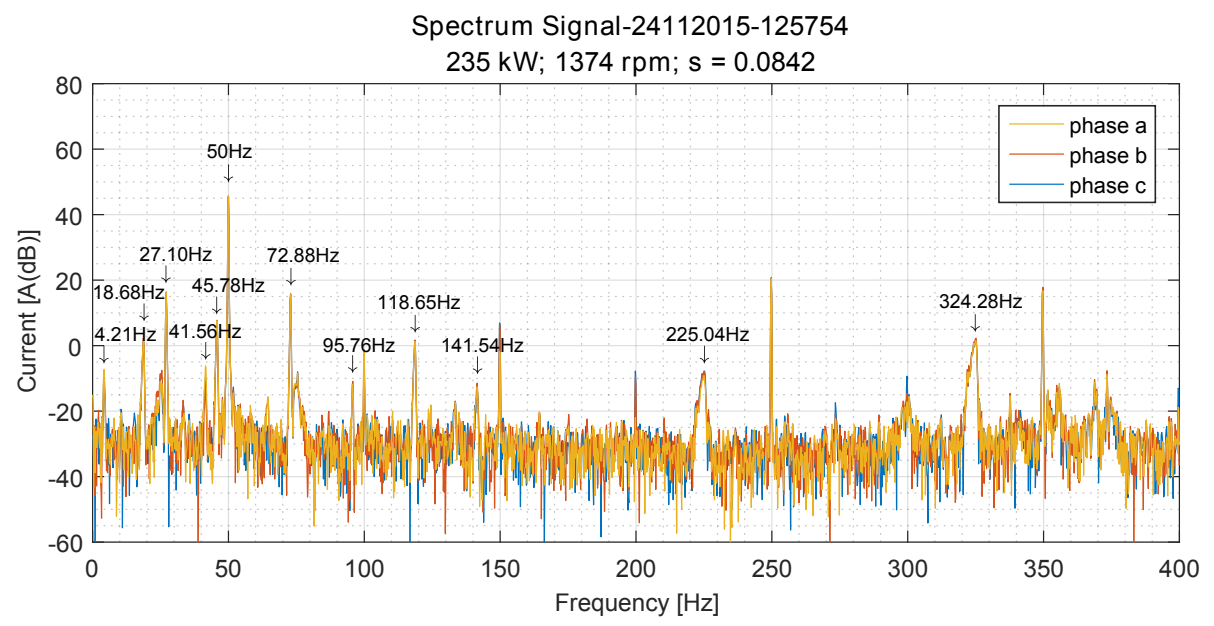

Figure 5: Frequency spectrum of stator current for signal 24112015-125754.

A decrease in the supply frequency amplitude was expected, considering the decrease in active power delivery from $825 \mathrm{~kW}$ to $235 \mathrm{~kW}$. However, the effect on its harmonics is different. In this test case, even harmonics show higher values than in test case 1, whereas odd harmonics are smaller. Despite this, odd harmonics present higher amplitudes than the even ones in this test case, as in test case 1 . A phase-to-phase comparison shows disparity in the amplitudes for harmonics $150 \mathrm{~Hz}$ and $300 \mathrm{~Hz}$, being higher in phases $\mathrm{b}$ and $\mathrm{c}$ than in phase a. The same occurs for harmonic $200 \mathrm{~Hz}$ where the disparity observed is ever larger.

Another observation is that the total sum of the main frequencies os the stator and rotor is now a subtraction (due to the sub-synchronous speed), falling now to the left of the supply frequency: $45.78 \mathrm{~Hz}$. Its amplitude level is similar to the previous one (around $7 \mathrm{~dB}$ ).

All potential fault frequencies have been calculated for signal 24112015125754, and summarized in Table 5. 


\begin{tabular}{|c|c|c|c|c|}
\hline Fault & \multicolumn{4}{|c|}{ Frequencies $(\mathrm{Hz})$} \\
\hline \multirow{2}{*}{$f_{b r b}(\mathrm{eq}(4))$} & 41.57 & & & \\
\hline & 58.41 & & & \\
\hline \multirow{2}{*}{$f_{b r b}(\mathrm{eq}(5))$} & 49.99 & 233.11 & 324.68 & \\
\hline & 58.41 & 224.70 & 316.26 & \\
\hline \multirow{2}{*}{$f_{b e, o}(\mathrm{eq}(7))$} & 23.26 & 96.51 & 169.76 & \\
\hline & 123.24 & 196.49 & 269.74 & \\
\hline \multirow{2}{*}{$f_{b e, i}(\operatorname{eq}(8))$} & 59.89 & 169.76 & 279.63 & \\
\hline & 159.86 & 269.74 & 379.61 & \\
\hline \multirow{2}{*}{$f_{s t}(\mathrm{eq}(9))$} & 27.10 & 4.21 & 18.68 & \\
\hline & 72.88 & 95.77 & 118.66 & \\
\hline \multirow{2}{*}{$f_{e c c, H F}($ eq $(10))$} & 1606.54 & 1706.52 & 1806.50 & \\
\hline & 1698.1 & 1798.08 & 1898.06 & \\
\hline \multirow{2}{*}{$f_{e c c, L F}($ eq $(11))$} & 27.10 & 4.21 & 18.68 & \\
\hline & 72.88 & 95.77 & 118.66 & \\
\hline \multirow{2}{*}{$f_{H R U}($ eq $(12))$} & 224.70 & 499.38 & 774.07 & 1048.75 \\
\hline & 324.68 & 599.36 & 874.04 & 1148.73 \\
\hline \multirow{2}{*}{$f_{F R U}($ eq $(13))$} & 27.10 & 4.21 & 18.68 & 41.57 \\
\hline & 72.88 & 95.77 & 118.66 & 141.55 \\
\hline
\end{tabular}

Table 5: Calculated fault frequencies for Signal 24112015-125754.

Once again, fault frequencies related to $f_{s t}, f_{e c c, L F}$ and $f_{F R U}$, and $f_{H R U}$ components can be identified. Considering the fault-related components, conclusions similar to test case 1 can be extracted: higher amplitudes are observed for the odd sub-harmonics than for the even ones. The amplitude levels of each sub-harmonic are similar when compared individually to those in test 1 . For this test case, however, the difference in the amplitude per phase for peak $\kappa=4$ and $l=-1$ is not noticeable, unlike the previous case.

For $f_{H R U}$ first pair of harmonics, a crest form is obtained as before, although it appears narrower. In this case, the left and right sub-harmonics do not present the same amplitude, the left-side one being smaller.

\subsection{Test case 3. Lower load E sub-synchronous speed}

Test case 3 is similar to test case 2 (being low load and sub-synchronous speed). However the slip for this state differs significantly, rising to $18 \%$. The raw current data for stator and rotor are shown in Figure 6, measured on 22/05/2016 at 03:27:01. The limits for the axes are kept constant for comparison purposes (i.e. same two-second zoom). It can be appreciated once again that steady-state conditions are met, giving around $8 \%$ the total current amplitude difference during the acquisition.

\begin{tabular}{c|c|c|c|c|c} 
& rms stator $[\mathbf{A}]$ & rms rotor $[\mathbf{A}]$ & f stator $[\mathrm{Hz}]$ & f rotor $[\mathrm{Hz}]$ & slip \\
\hline Phase a & 159.63 & 114.91 & & & \\
Phase b & 157.73 & 114.23 & 49.98 & 8.97 & 0.1794 \\
Phase c & 159.00 & 114.73 & & &
\end{tabular}

Table 6: Stator and rotor current parameters for signal 22052016-032701.

Table 6 presents the main parameters extracted from the waveforms. The differences found in the stator and rotor current rms amplitudes are less than 

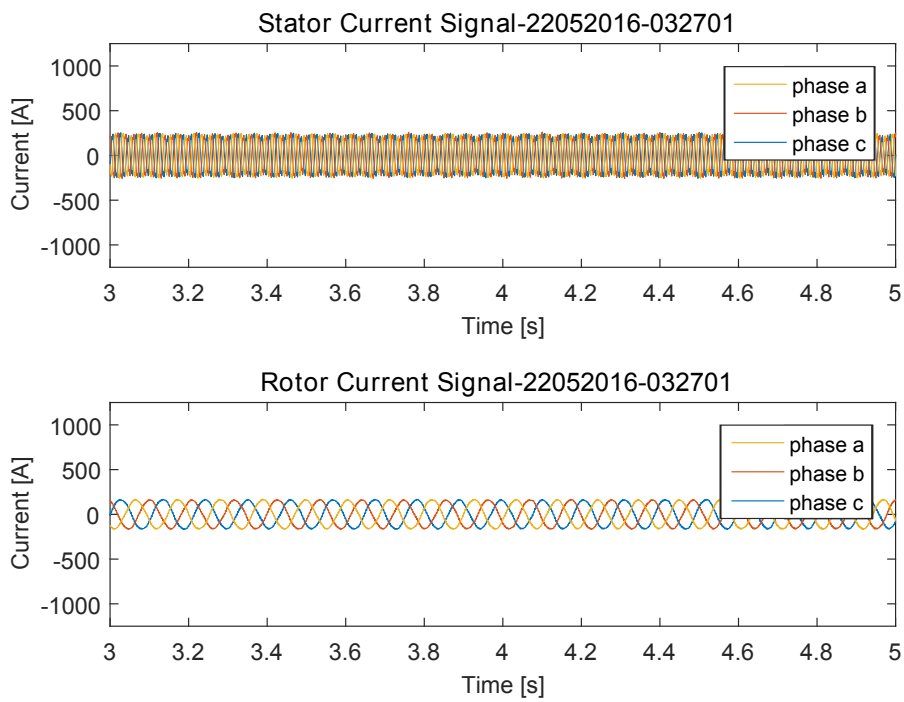

Figure 6: Stator and rotor currents at lower load and lower sub-synchronous speed (2s zoom).

$1.2 \%$ for the stator and practically negligible for the rotor. The highest amplitude of the rms stator current is found for phase a. The slip calculated for this state is 0.1794 , the highest among all cases presented.

FFT is then applied to the stator current (Figure 7), and peak search and identification performed.

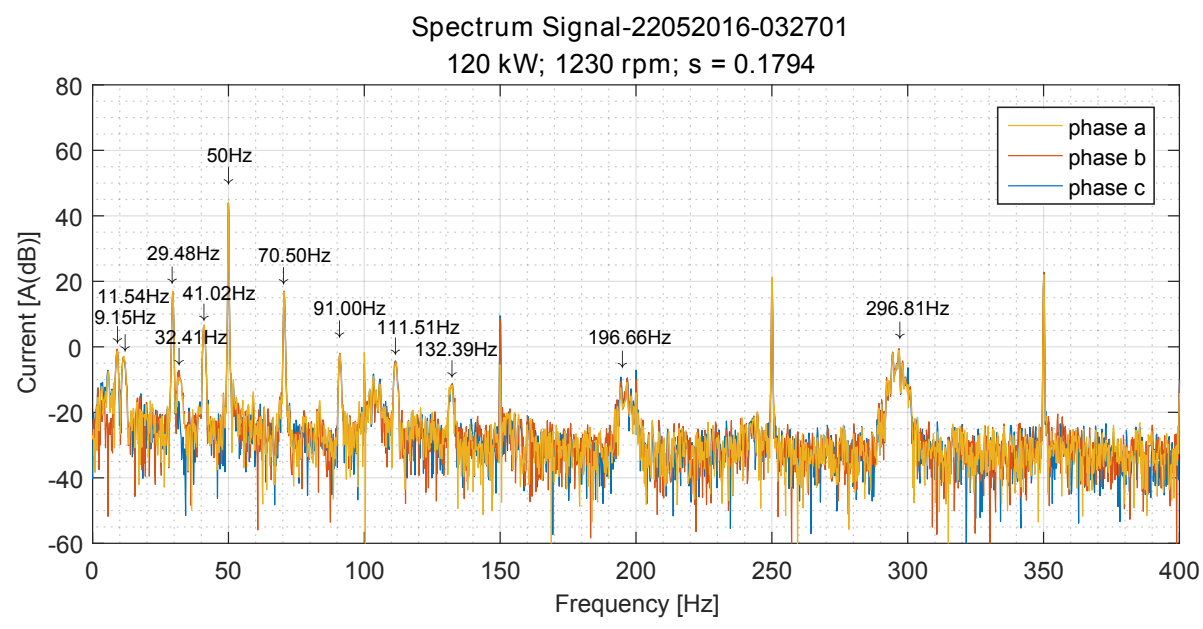

Figure 7: Frequency spectrum of stator current for signal 22052016-032701.

The amplitudes found for the supply frequency and the odd and even harmonics are similar to those found in test case 2, which is again as expected, 
considering the loads are alike. Once again, the odd harmonics present higher amplitudes than the even ones, which is consistent throughout the three test cases.

Regarding the total sum of the main frequencies of the stator and rotor, which is $41.02 \mathrm{~Hz}$, the same amplitude is obtained (around $7 \mathrm{~dB}$ ), again falling to the left of the supply frequency (sub-synchronous speed).

All potential fault frequencies have been calculated for signal 22052016032701, and summarized in Table 7.

\begin{tabular}{l|cccc} 
Fault & Frequencies (Hz) & & \\
\hline$f_{b r b}($ eq $(4))$ & 32.05 & & & \\
& 67.91 & & & \\
$f_{b r b}($ eq $(5))$ & 32.05 & 196.10 & 278.13 & \\
\hline \multirow{2}{*}{$f_{b e, o}($ eq $(7))$} & 49.98 & 214.03 & 296.06 & \\
& 15.64 & 81.26 & 146.89 & \\
$f_{b e, i}($ eq $(8))$ & 115.60 & 181.22 & 246.85 & \\
& 48.45 & 146.89 & 245.32 & \\
\multirow{2}{*}{$f_{s t}($ eq $(9))$} & 148.41 & 246.85 & 345.28 & \\
& 29.47 & 8.97 & 11.54 & \\
\multirow{2}{*}{$f_{e c c, H F}($ eq $(10))$} & 1444.44 & 1544.40 & 1644.36 & \\
& 1526.47 & 1626.43 & 1726.39 & \\
$f_{\text {ecc }, L F}($ eq $(11))$ & 29.47 & 8.97 & 11.54 & \\
\hline \multirow{2}{*}{$f_{H R U}($ eq $(12))$} & 70.49 & 90.99 & 111.50 & \\
\multirow{2}{*}{$f_{F R U}($ eq $(13))$} & 196.10 & 442.18 & 688.27 & 934.35 \\
& 296.06 & 542.14 & 788.26 & 1034.31 \\
& 29.47 & 8.97 & 11.54 & 32.05 \\
& 70.49 & 90.99 & 111.50 & 132.01
\end{tabular}

Table 7: Calculated fault frequencies for Signal 22052016-032701.

The peaks found in the spectrum match again with the $f_{s t}, f_{\text {ecc,LF }}$ and $f_{F R U}$, and $f_{H R U}$ formulae, the same as for test cases 2 and 3 . Table 7 shows the calculations. Note that in this test case, the peaks falling to the left of the supply frequency are shifted to the right and those falling to the right of the supply frequency move to the left when compared with test case 2 . This is due to the increase in the slip's value. With regards to the fault-related components, it can be observed from Figure 7 that for $\kappa=1$ and $\kappa=4$, the peak amplitudes are similar, whereas the amplitude for sub-harmonic $\kappa=2$ is higher for test case 3 than for test case 2, and the opposite for sub-harmonic $\kappa=3$.

For this test case, there is a slight difference in the amplitudes for subharmonic $\kappa=4$ and $l=-1$ per phase, being slightly higher in phases a and $\mathrm{b}$ than in phase $\mathrm{c}$.

As per $f_{H R U}$ first pair of harmonics, several peaks together as in a crest form are obtained once again. In this case, there is a $10 \mathrm{~dB}$ increment from the left-side peak to the right-side one, comparable with the amplitude levels found for $f_{F R U} \kappa=2,3,4$ sub-harmonics. 


\section{Discussion}

Three test cases under different wind turbine operating conditions have been considered to illustrate the in-service wind turbine. The results show evidence that the rotor generator is unbalanced due to a fault in the stator winding.

Examining the currents, a phase-to-phase difference of around $1.5 \%$ can be found in the rms amplitudes, which is not consistent across different load levels.

Odd and even supply frequency harmonics are present in the spectrum with different amplitudes across the test cases presented. These are due to unbalanced voltage supply or magnetic saturation in the wind turbine under study, which have been intensified by the generator's unbalance.

The amplitude of the supply frequency decreases with load, as expected, whereas the odd and even harmonics behaves differently. For all test cases however, the odd harmonics show higher amplitudes than the even ones.

Furthermore, load does not seem to have any influence on the total sum of the main stator and rotor frequencies, which is constant for all three cases (around $7 \mathrm{~dB}$ ).

As per the rest of the peaks, the same fault-related frequencies are obtained across all test cases. Analysing the amplitudes of the peaks, several events are observed:

- The fault-related first sub-harmonic's amplitude (corresponding to $\kappa=1$ ) is the highest one for the three test cases.

- Odd fault-related sub-harmonics present higher amplitudes than even ones across all tests.

- Fault-related sub-harmonics' amplitudes do not vary significantly with load.

- For low loads, the left-side of the healthy related components shows lower amplitude than the right-side one.

The fact that a crest form is obtained around $f_{H R U}$ supports the diagnosis of rotor unbalance, since further faulty rotor frequency components arise around it in the presence of the mentioned fault.

\section{Conclusions and future work}

A comprehensive review of the techniques available to monitor the induction generator of wind turbines has been carried out. The most suitable technique has been identified and used to perform the study presented in this paper. Unlike previous studies that show results on current signature analysis based on laboratory benches or model-based simulated data, the doubly-fed induction generator of an actual in-service wind turbine has been analysed through stator current signature analysis via Fast Fourier Transform during steady-state periods.

After calculating the potential fault-related frequency components as per the formulae presented in Section 3, it has been possible to identify the full spectral components obtained for the three test cases under different wind turbine operating conditions. 
The supply frequency harmonics as well as the oscillating torque effect component are clearly present on the spectrum. These components, however, are not necessarily fault indicators since they can be due to inherent machine design and/or load conditions. It is the increase in the amplitude of these components that will indicate the presence of a fault. The rest of the peaks observed in the spectrum indicate rotor electrical unbalance due to stator winding faults. They appear across different conditions of rated power and rotational speed, although the amplitudes of the different sub-harmonics is case-dependent. Summarising, potential fault frequencies have been detected and monitored in an operational wind turbine although further work is required to validate the monitoring technique against a final diagnose.

Current signature analysis can therefore be implemented on condition monitoring systems for DFIG wind turbines. In this way, incipient faults can be identified before the generator becomes non-operational, following the trend to move away from corrective maintenance towards predictive actions.

Future work appoints towards advanced signal processing techniques suitable for transient periods, common in DFIG-wind turbines, in combination with novel fault diagnosis methods. In this scenario, wavelets seem to be the trend for non-stationary signals' processing [30, 32, 54]. Other approaches presented recently by [55] show STFT and SFTT as effective methods. In [56] a new technique consisting in Harmonic Order Tracking Analysis (HOTA) is presented, which is valid both for stationary and non-stationary regimes. All these possibilities are being investigated, together with novel diagnosis techniques, in order to develop advanced condition monitoring systems for the induction generator of wind turbines.

\section{Acknowledgements}

This project has received funding from the European Union Horizon 2020 research and innovation programme under the Marie Sklodowska-Curie grant agreement No 642108, AWESOME Project. Special acknowledgement to Ingeteam Service S.A. (part of the AWESOME Project Consortium) who provided the wind turbine data.

\section{References}

[1] M. J. Kabir, A. M. Oo, N. Rabbani, A brief review on offshore wind turbine fault detection and recent development in condition monitoring based maintenance system, in: IEEE Power Engineering Conference AUPEC, 2015, pp. 1-7.

[2] S. Sheng, Improving component reliability through performance and condition monitoring data analysis, Tech. rep., Wind Farm Data Management \& Analysis North America (2015). 
[3] P. Tchakoua, R. Wamkeue, M. Ouhrouche, F. Slaoui-Hasnaoui, T. A. Tameghe, G. Ekemb, Wind turbine condition monitoring: State-of-the-art review, new trends, and future challenges, Energies 7 (4) (2014) 2595-2630.

[4] U. Shipurkar, K. Ma, H. Polinder, F. Blaabjerg, J. A. Ferreira, A review of failure mechanisms in wind turbine generator systems, in: IEEE Power Electronics and Applications (EPE'15 ECCE-Europe), 2015 17th European Conference, 2015, pp. 1-10.

[5] C. A. Rieg, C. J. Smith, C. J. Crabtree, Monitoring wind turbine loading using power converter signals, in: Journal of Physics Conference Series 749, 2016.

[6] C. J. Crabtree, S. Djurovic, P. J. Tavner, A. Smith, Condition monitoring of a wind turbine dfig by current or power analysis, in: Power Electronics, Machines and Drives (PEMD), 5th IET International Conference, IET, 2010, pp. 1-6.

[7] S. Djurovic, S. Williamson, A. Renfrew, Dynamic model for doubly-fed induction generators with unbalanced excitation, both with and without winding faults, IET Electric Power Applications 3 (3) (2009) 171-177.

[8] S. Williamson, S. Djurovic, Origins of stator current spectra in dfigs with winding faults and excitation asymmetries, IEEE International Electric Machines and Drives Conference, IEMDC'09 9 (2009) 563-570.

[9] P. J. Tavner, Review of condition monitoring of rotating electrical machines, IET Electric Power Applications 2 (4) (2007) 215-247.

[10] P. V. J. Rodriguez, M. Negrea, A. Arkkio, A simplified scheme for induction motor condition monitoring, Mechanical Systems and Signal Processing 22 (5) (2008) 1216-1236.

[11] G. B. Kliman, J. Stein, Methods of motor current signature analysis, Electric Machines and Power Systems 20 (5) (1992) 463-474.

[12] F. P. G. Márquez, A. M. Tobias, J. M. P. Pérez, M. Papaelias, Condition monitoring of wind turbines: Techniques and methods, Renewable Energy 46 (2012) 169-178.

[13] W. Qiao, D. Lu, A survey on wind turbine condition monitoring and fault diagnosis - Part I: Components and subsystems, IEEE Transactions on Industrial Electronics 62 (10) (2015) 6536-6545.

[14] W. Qiao, D. Lu, A survey on wind turbine condition monitoring and fault diagnosis - Part II: Signals and signal processing methods, IEEE Transactions on Industrial Electronics 62 (10) (2015) 6546-6557.

[15] W. Qiao, P. Zhang, M.-Y. Chow, Condition monitoring, diagnosis, prognosis, and health management for wind energy conversion systems, IEEE Transactions on Industrial Electronics 62 (10) (2015) 6533-6535. 
[16] W. Y. Liu, B. P. Tang, J. G. Han, X. N. Lu, N. N. Hu, Z. Z. He, The structure healthy condition monitoring and fault diagnosis methods in wind turbines: A review, Renewable and Sustainable Energy Reviews 44 (2015) $466-472$.

[17] Y. Amirat, M. E. H. Benbouzid, E. Al-Ahmar, B. Bensaker, S. Turri, A brief status on condition monitoring and fault diagnosis in wind energy conversion systems, Renewable and Sustainable Energy Reviews 13 (9) (2009) 2629-2636.

[18] S. Nandi, H. A. Toliyat, X. Li, Condition monitoring and fault diagnosis of electrical motors - a review, IEEE Transactions on Energy Conversion 20 (4) (2005) 719-729.

[19] M. E. H. Benbouzid, A review of induction motors signature analysis as a medium for faults detection, IEEE Transactions on Industrial Electronics 47 (5) (2000) 984-993.

[20] A. Siddique, G. Yadava, B. Singh, A review of stator fault monitoring techniques of induction motors, IEEE Transactions on Energy Conversion 20 (1) (2005) 106-114.

[21] M. E. H. Benbouzid, G. B. Kliman, What stator current processing-based technique to use for induction motor rotor faults diagnosis?, IEEE Transactions on Energy Conversion 18 (2) (2003) 238-244.

[22] Z. Gao, X. Liu, M. Z. Chen, Unknown input observer-based robust fault estimation for systems corrupted by partially decoupled disturbances, IEEE Transactions on Industrial Electronics 63 (4) (2016) 2537-2547.

[23] X. Liu, Z. Gao, Robust finite-time fault estimation for stochastic nonlinear systems with brownian motions, Journal of the Franklin Institute.

[24] E. Gonzalez, M. Reder, J. Melero, SCADA alarms processing for wind turbine component failure detection, Journal of Physics: Conference Series 753 (7) (2016) 072019.

[25] J. Tautz-Weinert, S. J. Watson, Using scada data for wind turbine condition monitoring - a review, IET Renewable Power Generation.

[26] Y. Lin, L. Tu, H. Liu, W. Li, Fault analysis of wind turbines in China, Renewable and Sustainable Energy Reviews 55 (2016) 482-490.

[27] J. Carroll, A. McDonald, D. McMillan, Failure rate, repair time and unscheduled O\&M cost analysis of offshore wind turbines, Wind Energy 19 (2015) 1107-1119.

[28] F. Spinato, P. J. Tavner, G. J. W. Bussel, E. Koutoulakos, Reliability of wind turbine subassemblies, IET Renewable Power Generation 3 (4) (2008) 387-401. 
[29] A. Bellini, F. Filippetti, C. Tassoni, G.-A. Capolino, Advances in diagnostic techniques for induction machines, IEEE Transactions on Industrial Electronics 12 (55) (2008) 4109-4126.

[30] Y. Gritli, L. Zarri, C. Rossi, F. Filippetti, G.-A. Capolino, D. Casadei, Advanced diagnosis of electrical faults in wound-rotor induction machines, IEEE Transactions on Industrial Electronics 60 (9) (2013) 4012-4024.

[31] A. H. Bonnett, C. Yung, Increased efficiency versus increased reliability, IEEE Industry Applications 14 (1) (2008) 29-36.

[32] S. J. Watson, B. J. Xiang, W. Yang, P. J. Tavner, C. J. Crabtree, Condition monitoring of the power output of wind turbine generators using wavelets, IEEE Transactions on Energy Conversion 25 (3) (2010) 715-721.

[33] S. A. Shehata, H. S. El-Goharey, M. I. Marei, A. K. Ibrahim, Detection of induction motors rotor/stator faults using electrical signatures analysis, in: International Conference on Renewable Energies and Power Quality (ICREPQ13) Bilbao (Spain), 2013.

[34] S. Djurovic, C. J. Crabtree, P. J. Tavner, A. Smith, Condition monitoring of wind turbine induction generators with rotor electrical asymmetry, IET Renewable Power Generation 6 (4) (2012) 207-216.

[35] Y. Amirat, V. Choqueuse, M. Benbouzid, J.-F. Charpentier, Bearing fault detection in dfig-based wind turbines using the first intrinsic mode function, in: XIX International Conference on Electrical Machines (ICEM), 2010, pp. $1-6$.

[36] A. Stefani, A. Yazidi, C. Rossi, F. Filippetti, D. Casadei, G.-A. Capolino, Doubly fed induction machines diagnosis based on signature analysis of rotor modulating signals, IEEE Transactions on Industry Applications 44 (6) (2008) 1711-1721.

[37] D. Shah, S. Nandi, P. Neti, Stator-interturn-fault detection of doubly fed induction generators using rotor-current and search-coil-voltage signature analysis, IEEE Transactions on Industry Applications 45 (5) (2009) 18311842.

[38] Q. F. Lu, Z. T. Cao, E. Ritchie, Model of stator inter-turn short circuit fault in doubly-fed induction generators for wind turbine, in: IEEE 35th Annual Power Electronics Specialists Conference, 2004, pp. 932-937.

[39] A. Yazidi, H. Henao, G. Capolino, D. Casadei, F. Filippetti, C. Rossi, Simulation of a doubly-fed induction machine for wind turbine generator fault analysis, in: 5th IEEE International Symposium on Diagnostics for Electric Machines, Power Electronics and Drives (SDEMPED), 2005, pp. $1-6$. 
[40] C. Sheng, Z. Li, L. Qin, Z. Guo, Y. Zhang, Recent progress on mechanical condition monitoring and fault diagnosis, Procedia Engineering 15 (2011) $142-146$.

[41] A. K. S. Jardine, D. Lin, D. Banjevic, A review on machinery diagnostics and prognostics implementing condition-based maintenance, Mechanical Systems and Signal Processing (20) (2006) 1483-1510.

[42] B. Lu, Y. Li, X. Wu, Z. Yang, A review of recent advances in wind turbine condition monitoring and fault diagnosis, in: IEEE Power Electronics and Machines in Wind Applications (PEMWA), 2009, pp. 1-7.

[43] B. Trajin, M. Chabert, J. Regnier, J. Faucher, Hilbert versus concordia transform for three-phase machine stator current time-frequency monitoring, Mechanical Systems and Signal Processing 23 (2009) 2648-2657.

[44] L. Sadiki, S. El Hani, A. Echchaachouai, S. Guedira, Rotor electrical fault detection in wound rotor of asynchronous machine by gabor transform: application in wind turbine and offshore turbine generator, in: 3rd International Renewable and Sustainable Energy Conference (IRSEC), 2015, pp. $1-5$.

[45] Y. Yang, Z. Peng, G. Meng, W. Zhang, Spline-Kernelled Chirplet transform for the analysis of signals with time-varying frequency and its application, IEEE Transactions on Industrial Electronics 59 (3) (2012) 1612-1621.

[46] W. Yang, P. J. Tavner, W. Tian, Wind turbine condition monitoring based on an improved Spline-Kernelled Chirplet transform, IEEE Transactions on Industrial Electronics 62 (10) (2015) 6565-6574.

[47] W. T. Thomson, M. Fenger, Current signature analysis to detect induction motor faults, IEEE Industry Applications Magazine 7 (4) (2001) 26-34.

[48] G. Acosta, C. Verucchi, E. Gelso, A current monitoring system for diagnosing electrical failures in induction motors, Mechanical Systems and Signal Processing 20 (4) (2006) 953-965.

[49] A. Bellini, F. Filippetti, G. Franceschini, C. Tassoni, Quantitative evaluation of induction motor broken bars by means of electrical signature analysis, IEEE Transactions on Industry Applications 37 (5) (2001) 12481255 .

[50] J. H. JJung, J. J. Lee, B. H. Kwon, Online diagnosis of induction motors using MCSA, IEEE Transactions on Industrial Electronics 53 (6) (2006) $1842-1852$.

[51] G. M. Joksimovic, The detection of inter-turn short circuits in the stator windings of operating motors, IEEE Transactions on Industrial ELectronics 47 (5) (2000) 1078-1084. 
[52] H. Douglas, P. Pillay, P. Barendse, The detection of interturn stator faults in doubly-fed induction generators, in: Fourtieth IAS Annual Meeting. Conference Record of the 2005 Industry Applications Conference, 2005, pp. 1097-1102.

[53] J. Faiz, S. Moosavi, Eccentricity fault detection - from induction machines to dfig - a review, Renewable and Sustainable Energy Reviews 55 (2016) 169-179.

[54] K. S. Gaeid, H. W. Ping, M. K. Masood, L. Szabo, Survey of wavelet fault diagnosis and tolerant of induction machines with case study, International Review of Electrical Engineering (IREE) 7 (3) (2012) 4437-4457.

[55] J. M. C. López, Técnicas optimizadas de análisis de señal en dominio tiempo-frecuencia para el diagnóstico de máquinas de inducción en régimen transitorio, Ph.D. thesis, Universidad Politécnica de Valencia (2016).

[56] A. S. Baño, Desarrollo de tecnicas avanzadas de diagnostico de maquinas electricas validas para cualquier regimen de funcionamiento, Ph.D. thesis, Universitat Politecnica de Valencia (2014). 